\title{
Alloying Element Nitride Development in Ferritic Fe-Based Materials Upon Nitriding: A Review
}

\author{
T. Steiner and E.J. Mittemeijer
}

(Submitted March 8, 2016; published online April 26, 2016)

\begin{abstract}
With the aim of achieving a better understanding of the nitriding process of iron-based components (steels), as applied in engineering practice, the theoretical background and experimental observations currently available on the crystallographic, morphological, and compositional properties of the nitride precipitates in nitrided model binary and ternary, ferritic Fe-based alloys are summarily presented. Thermodynamic and kinetic considerations are employed in order to highlight their importance for the nitriding reaction and the resulting properties of the nitrided zone, thereby providing a more fundamental understanding of the nitriding process.
\end{abstract}

Keywords heat treatment, nitriding, steel, surface engineering

\section{Introduction}

Nitriding is a thermochemical surface treatment, by which nitrogen is introduced from an outer gas atmosphere, plasma, or salt bath into the surface adjacent regions of a component (Ref 1-3). The nitrogen absorbed at the surface will diffuse inwardly leading to the development of the so-called diffusion zone. At sufficiently high chemical potential of nitrogen in the nitrogen-donating medium (the "nitriding atmosphere"), iron may react directly with nitrogen leading to the development of a layer of iron nitride(s) on the specimen surface, the so-called compound layer, on top of the diffusion zone. This layer is generally composed of grains of $\gamma^{\prime}-\mathrm{Fe}_{4} \mathrm{~N}_{1-x}$ and $\varepsilon-\mathrm{Fe}_{3} \mathrm{~N}_{1+x}$ (Ref 2).

In pure iron and in plain carbon steels, upon slow cooling (from the nitriding temperature) or prolonged aging at lower temperatures, precipitation of $\gamma^{\prime}$ nitride from the nitrogensupersaturated ferrite matrix can occur in the diffusion zone with a characteristic needle shape ( $\operatorname{Ref} 4)$. Also, at temperatures smaller than say $150{ }^{\circ} \mathrm{C}$, the formation of an intermediate precipitate $\alpha^{\prime \prime}-\mathrm{Fe}_{16} \mathrm{~N}_{2}$ can occur (Ref 5,6).

Phase transformations can also occur in the compound layer upon cooling after nitriding. Thus, $\gamma^{\prime}$ may precipitate in $\varepsilon$ (giving rise to the typical "staircase microstructure") (Ref 7) and $\alpha$-Fe may precipitate (as needles) in $\gamma^{\prime}(\operatorname{Ref} 8$ ).

This paper is based on an invited keynote lecture presented at the 23rd IFHTSE Congress, organized by the ASM Heat Treating Society and the International Federation of Heat Treatment and Surface Engineering, April 18-21, 2016, in Savannah, GA, and has been expanded from the original presentation.

T. Steiner, Max Planck Institute for Intelligent Systems (Formerly Metals Research), Heisenbergstrasse 3, 70569 Stuttgart, Germany and Robert Bosch GmbH, Robert-Bosch-Strasse 2, 71701 Schwieberdingen, Germany; and E.J. Mittemeijer, Max Planck Institute for Intelligent Systems (Formerly Metals Research), Heisenbergstrasse 3, 70569 Stuttgart, Germany and Institute for Materials Science, University of Stuttgart, Heisenbergstrasse 3, 70569 Stuttgart, Germany. Contact e-mail: tobias.steiner2@de. bosch.com.
If the nitrided iron-based material contains alloying elements $(\mathrm{Me})$ with an affinity for nitrogen stronger than that of iron for nitrogen, the nitrogen in the diffusion zone will interact with the alloying element. In the case of ferritic materials (nitriding temperatures in the range $510-580^{\circ} \mathrm{C}$ ), this usually means the precipitation of more or less fine alloying element nitrides. Examples of such papers (with $\mathrm{Me}$ as indicated): $\mathrm{Ti}$ (Ref 9-11), V (Ref 12-16), Cr (Ref 17-24), Mo (Ref 9, 25-27), Al (Ref 28-33), Si (Ref 34-37), and Mn (Ref 38-42). In the case of austenitic materials, a strongly nitrogen-supersaturated (up to 25 at.\%) solid solution may develop at sufficiently low temperatures (say $450{ }^{\circ} \mathrm{C}$ ) to suppress the mobility of the alloying element $\mathrm{Me}$ and thus the precipitation of alloying element nitride particles (pp. 169-170 in Ref 43 and Ch. 14 in Ref 3).

In the present paper, the focus lies on the development of alloying element nitrides in the ferritic diffusion zone during the nitriding process.

\section{Strength of the Alloying Element (Me)-Nitrogen (N) Interaction}

In order to determine the nitriding response that can be expected for $\mathrm{Me}$, with nitrogen, $\mathrm{N}$, in iron-based materials containing the nitride forming alloying element, knowledge of the strength of interaction of the alloying elements present in the system is helpful. Alloying elements having a strong nitrogen affinity are likely to form very stable compounds with nitrogen, i.e., the nitrides of these alloying elements will have a strongly negative Gibbs energy of formation from the elements. Alloying elements commonly present in steel and which can form nitrides in the matrix are $\mathrm{Ti}, \mathrm{V}, \mathrm{Al}, \mathrm{Si}, \mathrm{Cr}$, and $\mathrm{Mo}$ (see Table 7.1 in Ref 3). Alloying elements as $\mathrm{Ni}, \mathrm{Co}$, or $\mathrm{Cu}$ can only form nitrides at chemical potentials of nitrogen even higher than those required for the development of iron nitrides (at the surface) and are therefore not considered here.

If the $\mathrm{MeN}_{x}$ particle forms within a grain of the ferrite matrix, it is constrained by the surrounding matrix and strains arise due to the volumetric mismatch of the nitride precipitate and the ferrite matrix (see Table 1) and the crystallographic 
Table 1 Lattice parameters $(a, c)$, number of Me atoms per unit cell (z), and volume misfit $\left(\frac{\Delta v}{v}\right)$ between the nitride and the pure ferrite matrix, for various alloying element nitride phases

\begin{tabular}{|c|c|c|c|c|c|}
\hline Nitride & Crystal lattice & Lattice parameters, $\AA$ & $z$ & $\frac{\Delta v}{v}, \%$ & Reference \\
\hline TiN & Cubic & $a=4.2417$ & 4 & 62 & 91 \\
\hline $\mathrm{VN}$ & Cubic & $a=4.139$ & 4 & 51 & 91 \\
\hline AlN & Hexagonal & $\begin{array}{l}a=3.11 \\
c=4.979\end{array}$ & 4 & 77 & 92 \\
\hline $\mathrm{Mo}_{2} \mathrm{~N}$ & Cubic & $a=4.163$ & 4 & 53 & 91 \\
\hline $\mathrm{CrN}$ & Cubic & $a=4.14$ & 4 & 51 & 91 \\
\hline $\mathrm{Cr}_{2} \mathrm{~N}$ & Hexagonal & $\begin{array}{l}a=4.795 \\
c=4.469\end{array}$ & 6 & 26 & 93 \\
\hline $\mathrm{Si}_{3} \mathrm{~N}_{4}$ & Hexagonal & $\begin{array}{l}a=7.71 \\
c=2.908\end{array}$ & 6 & 112 & 94 \\
\hline$\delta_{3}-\mathrm{MoN}$ & Hexagonal & $\begin{array}{l}a=5.63 \\
c=5.736\end{array}$ & 8 & 67 & 95 \\
\hline $\mathrm{CrMoN}_{2}$ & Hexagonal & $\begin{array}{l}a=2.85 \\
c=15.63\end{array}$ & 6 & 56 & 46 \\
\hline
\end{tabular}

constraints as exposed at the precipitate/matrix interface. The total volumetric mismatch can be considered by comparing the molar volumes of the alloying element nitride, $v_{\mathrm{MeN}_{X}}$, and the molar volume of $\mathrm{Fe}$ in the ferritic matrix, $v_{\mathrm{Fe}}$, according to:

$\frac{\Delta v}{v}=\frac{v_{\mathrm{MeN}_{X}}-v_{\mathrm{Fe}}}{v_{\mathrm{Fe}}} \times 100 \%$

recognizing that upon precipitation one mole $\mathrm{MeN}_{x}$ develops from one mole $\mathrm{Me}$ atoms originally dissolved in the nitrogenless, parent ferrite lattice.

The strain energy, which arises during precipitation, may slow the nitride-precipitation process considerably. A striking case occurs for $\mathrm{Me}=\mathrm{Si}$ : although the precipitation of $\mathrm{Si}_{3} \mathrm{~N}_{4}$ is accompanied by the release of a large amount of chemical Gibbs energy $\left[210 \mathrm{~kJ} \mathrm{~mol}^{-1}\right.$ per mole $\mathrm{N}_{2}$ (Ref 3)], its development occurs at the expense of an even larger amount of strain energy, if full elastic accommodation of the misfit would occur $\left[523 \mathrm{~kJ} \mathrm{~mol}^{-1}\right.$ per mole $\mathrm{N}_{2}$ (Ref 3)]. This leads to silicon reacting only extremely slowly with the inwardly diffusing nitrogen (Ref 36).

In order to characterize this interplay of release of chemical Gibbs energy, $\Delta G_{\text {chem }}$, and expense of strain energy, $\Delta G_{\text {strain, }}$, an interaction parameter $I$ was proposed, defined as (Ref 3, 44):

$I=-\frac{\Delta G_{\text {chem }}}{\Delta G_{\text {strain }}}$.

It allows to arrange the reactivities of various $\mathrm{Me}$ with $\mathrm{N}$ in binary ferritic alloys in roughly this order: $\mathrm{Ti}>\mathrm{V}>\mathrm{Al}>$ $\mathrm{Cr}>\mathrm{Si}>\mathrm{Mo}$. Note that in binary Fe-Mn alloys, complex phase transformation reactions take place (Ref 38-42), which has led to its exclusion from this series.

\section{Crystal Structures of $\mathrm{MeN}_{x}$}

The most common composition and crystal structure of the alloying element nitride (as it (can) occur(s) for $\mathrm{Me}=\mathrm{Ti}, \mathrm{V}, \mathrm{Al}$, and $\mathrm{Cr}$ ) are described by the stoichiometry $\mathrm{MeN}$ and the rock salt $(\mathrm{NaCl})$ crystal structure. Yet, a large variety of crystal structures occurs for phases in the binary Me-N systems; an overview of nitride phases that can form in steels is presented in Ref 45. That listing is not exhaustive: for example, the $\delta$-MoN phase that develops by discontinuous precipitation (DP) in binary Fe-Mo alloys (Ref 27) has a complex hexagonal crystal structure, amorphous $\mathrm{Si}_{3} \mathrm{~N}_{4}$ is found to precipitate in $\mathrm{Fe}-\mathrm{Si}$ alloys (Ref 35, 36), and a ternary, layered hexagonal $\mathrm{CrMoN}_{2}$ nitride forms by DP upon prolonged nitriding of ternary $\mathrm{Fe}-\mathrm{Cr}-$ Mo alloys (Ref 46), etc.

\section{Precipitation Morphology and Microstructure}

The crystal structures of the nitride precipitates determine their shape and crystallographic orientation in the ferrite matrix. The most widely encountered crystal structure is the NaCl-type crystal structure. TiN, VN, cubic $\mathrm{AlN}, \mathrm{CrN}$, and $\mathrm{Mo}_{2} \mathrm{~N}$ (with $50 \%$ vacancies on the $\mathrm{N}$ sublattice) all precipitate in this modification. The good matching of the NaCl-type crystal structure to the bcc ferrite matrix crystal structure in the BakerNutting orientation relationship (OR) (Ref 47) at the $\{100\}_{\alpha-\mathrm{Fe}}$ habit planes determines the shape of the precipitates: they develop as finely distributed, usually nano-sized platelets on the $\{100\}_{\alpha-F e}$ planes of the ferrite matrix, (see Fig. 1). As they form largely homogeneously throughout the ferrite matrix, this microstructure is commonly referred to as continuously precipitated (CP) (Ref 3, 43). The fine distribution of nitride precipitates, their large volume mismatch and coherent nature of the platelet faces are the main origins of the high hardness and large residual microstresses that develop in the diffusion zone upon nitriding.

In binary Fe-Cr (Ref 18-20, 22), Fe-V (Ref 15) and Fe-Mo (Ref 27) alloys, as well as in ternary Fe-Cr-Mo (Ref 46, 48) and quaternary Fe-Cr-Mo-V (Ref 49) alloys, prolonged aging may lead to the development of a much coarser lamellar microstructure consisting of alternating ferrite and nitride lamellae, (see Fig. 2). This microstructure forms by a discontinuous, moving grain boundary-mediated mechanism (Ref 50, 51).

In $\mathrm{Fe}-\mathrm{Cr}$ and $\mathrm{Fe}-\mathrm{V}$ alloys, a discontinuous coarsening (DC) reaction occurs, which is driven by the reduction of precipitate - matrix interfacial area, loss of nitrogen supersaturation of the matrix and (misfit) stress relaxation (Ref 18). The DC reaction can be expressed in the following way: 


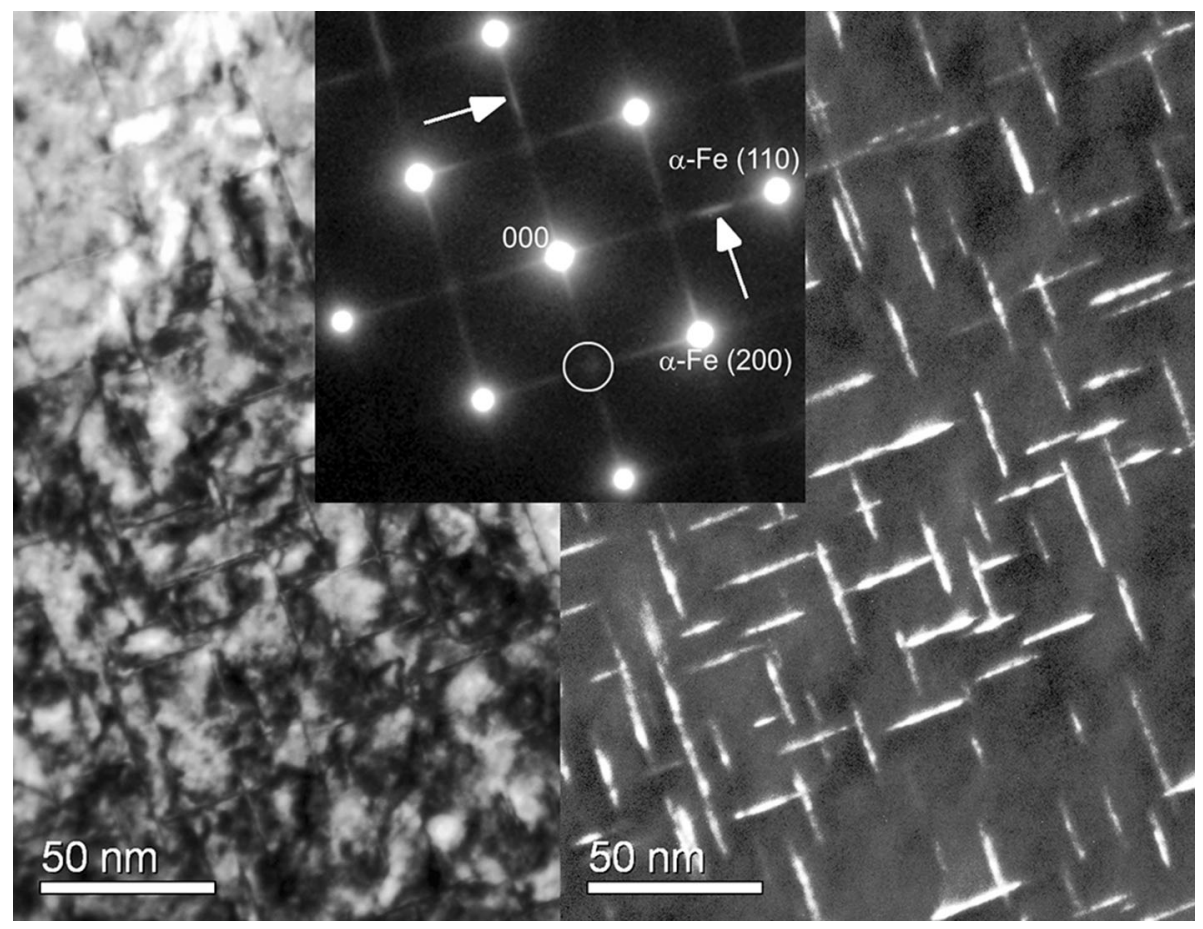

Fig. 1 TEM bright field (left), dark field (right) micrographs, and corresponding selected area diffraction pattern (SADP), of an Fe-2.0 at.\%Cr alloy specimen nitrided at $580{ }^{\circ} \mathrm{C}$ for $385 \mathrm{~h}$ with a nitriding potential of $0.1 \mathrm{~atm}^{-1 / 2}$ : The aperture for dark field imaging, employing the intersection of the streaked diffraction spots of $\mathrm{CrN}$ of two orientation variants, is indicated by the white circle; white arrows indicate the positions of intensity maxima along the streaks pertaining to $200_{\mathrm{CrN}}$-type spots. From Ref 83

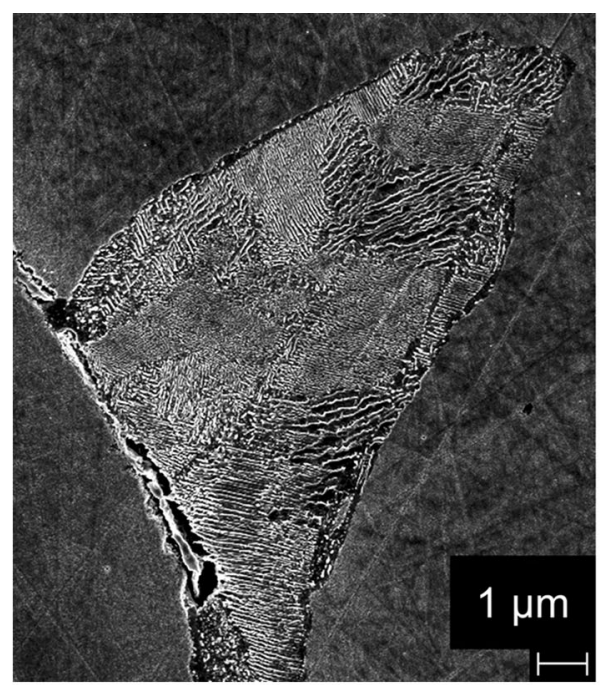

(a)

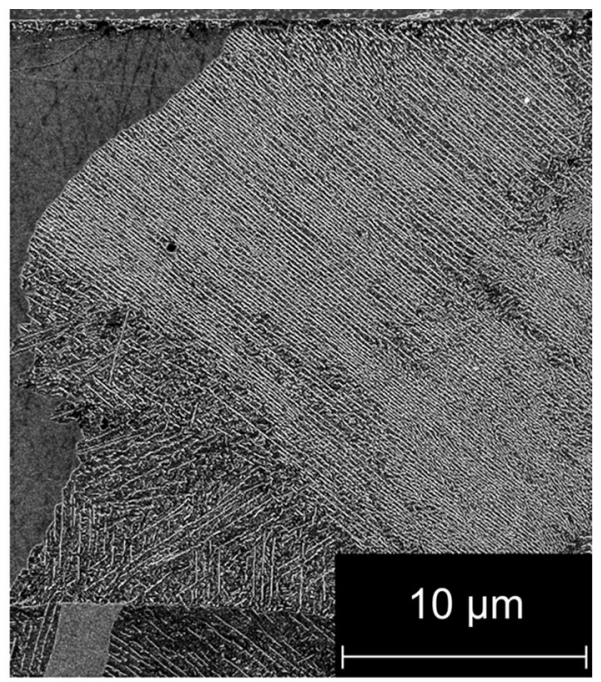

(b)

Fig. 2 SEM micrographs recorded from the cross-sections of (a) a DC region in $\mathrm{Fe}-1.81 \mathrm{~s}$ at $\% \mathrm{Cr}-0.25$ at. $\%$ Mo alloy after nitriding at $580{ }^{\circ} \mathrm{C}$ for $72 \mathrm{~h}$ with a nitriding potential of $0.1 \mathrm{~atm}^{-1 / 2}$. (b) DP regions in Fe-1.04 at $\% \mathrm{Cr}-1.01$ at.\%Mo alloy after nitriding at $580{ }^{\circ} \mathrm{C}$ for $72 \mathrm{~h}$ with a nitriding potential of $0.1 \mathrm{~atm}^{-1 / 2}$. From Ref 48

$\alpha^{\prime}+\beta^{\prime} \rightarrow \alpha+\beta$,

where $\alpha^{\prime}$ denotes the supersaturated, strained ferrite matrix, $\beta^{\prime}$ denotes the fine, (semi-)coherent $\mathrm{CP}$ nitride particles, $\alpha$ the relaxed ferrite matrix, and $\beta$ the coarsened nitride phase.

In binary Fe-Mo and ternary Fe-Cr-Mo alloys, a discontinuous precipitation (DP) reaction occurs, in which not only coarsening (as for DC) occurs, but which also involves a phase transformation of the initially precipitated, intermediate $\mathrm{CP}$ nitride phase to the thermodynamically more stable nitride phase of different composition and crystal structure: $\delta$-MoN forms from $\gamma-\mathrm{Mo}_{2} \mathrm{~N}$ in binary $\mathrm{Fe}-\mathrm{Mo}$ alloys and $\mathrm{CrMoN}_{2}$ forms from $\left(\mathrm{Cr}_{z} \mathrm{Mo}_{1-z}\right) \mathrm{N}_{(1+z) / 2}$ in low Cr/Mo-ratio FeCr-Mo alloys (Ref 46, 48). The additional contribution of the chemical energy released by formation of the more stable nitride phase accelerates the DP reaction as compared to the DC reaction (Ref 48). The reaction DP can be expressed in the following way: 
$\alpha^{\prime}+\beta \rightarrow \alpha+\delta$

where $\alpha^{\prime}$ denotes the supersaturated, strained ferrite matrix, $\beta$ denotes the intermediate CP nitride particles, $\alpha$ the relaxed ferrite matrix, and $\delta$ the thermodynamically stable DP nitride phase.

The consequence of the formation of the coarsened microstructure by both types of discontinuous reactions is a considerable loss of hardness and residual stresses in these regions, see e.g., Ref 24, 27, 48.

\section{Development of Nitrogen Content Depth Profiles}

The strength of the Me-N interaction also has predictive power for the shape of the nitrogen content depth profiles: the
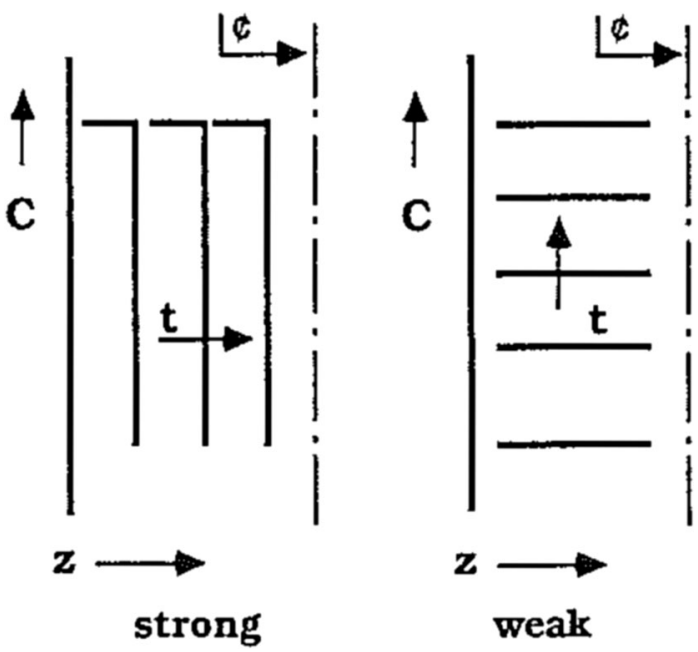

Fig. 3 Schematic temporal evolution of the nitrogen content depth profiles of strong (left) and weak (right) nitride forming elements. From Ref 29 stronger the interaction, the more immediate the dissolved alloying element will react with the inwardly diffusing nitrogen. Two extreme cases can be identified (Ref 29) (see Fig. 3): (i) The nitrogen content depth profiles of strong nitride forming elements have a rectangular shape of high (saturationlevel) nitrogen content near the surface and (after an abrupt transition) nil at depths larger than the nitrided region, as the alloying element reacts practically instantaneously with nitrogen upon its arrival at a certain depth in the specimen; only if all alloying element at the depth considered has precipitated, the inwardly diffusing nitrogen can reach larger depths. This behavior is, to good approximation, observed, for example, for the precipitation of TiN (Ref 9-11), VN (Ref 12-16), and CrN (Ref 17-24) at not too high nitriding temperatures. (ii) In case of weak nitride formers, the nitrogen content is of practically constant level throughout the depth of the specimen (of finite thickness), and this nitrogen level rises only slowly with proceeding precipitation (as a bucket that becomes filled with liquid). This behavior is, to good approximation, for example observed for the precipitation of $\mathrm{Mo}_{2} \mathrm{~N}$ (Ref 27), hexagonal AlN (Ref 52), and especially $\mathrm{Si}_{3} \mathrm{~N}_{4}$ (Ref 36). In practice, for cases of non-extreme Me-N interaction, nitrogen content depth profiles with more or less shallow nitrided case/unnitrided core transitions occur.

Upon comparing the nitriding behaviors of Fe-Mo and Fe-Si alloys, an interesting observation can be made: although the $\mathrm{Si}$ $\mathrm{N}$ interaction parameter $[\sim 0.4$, (Ref 3$)]$ is higher than that of Mo-N $(\sim 0.2)\left(\mathrm{Si}_{3} \mathrm{~N}_{4}\right.$ is a chemically very stable nitride but with a large volume misfit, whereas $\mathrm{Mo}_{2} \mathrm{~N}$ is a chemically relatively less stable nitride but with a moderate volume misfit), the nitrogen content depth profiles of nitride Fe-Si alloys are more shallow than those of Fe-Mo alloys, indicating that in fact $\mathrm{Si}$ is the weaker nitride forming element. The origin of this effect likely lies in the crystallography of the respective nitrides: on the one hand, $\mathrm{Mo}_{2} \mathrm{~N}$ has the $\mathrm{NaCl}$-type crystal structure (with, as a special feature, only $50 \%$ of the octahedral interstices of the Mo lattice occupied by N) and can thus adopt the favorable Baker-Nutting OR with the ferrite matrix allowing its comparatively easy nucleation. On the other hand, $\mathrm{Si}_{3} \mathrm{~N}_{4}$, with its complex hexagonal crystal structure, can precipitate in the bcc

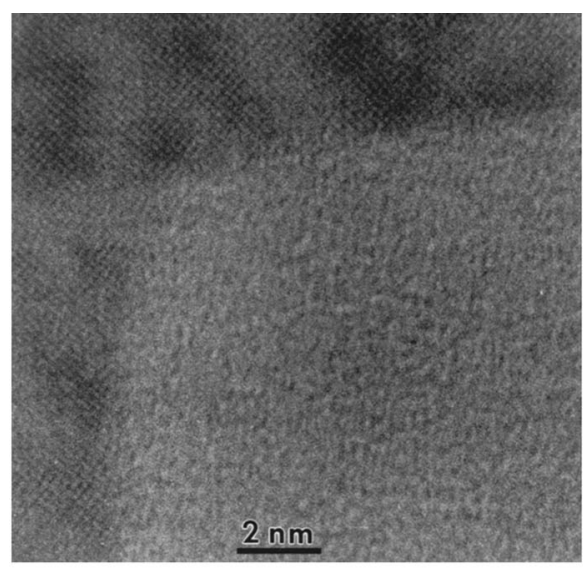

(a)

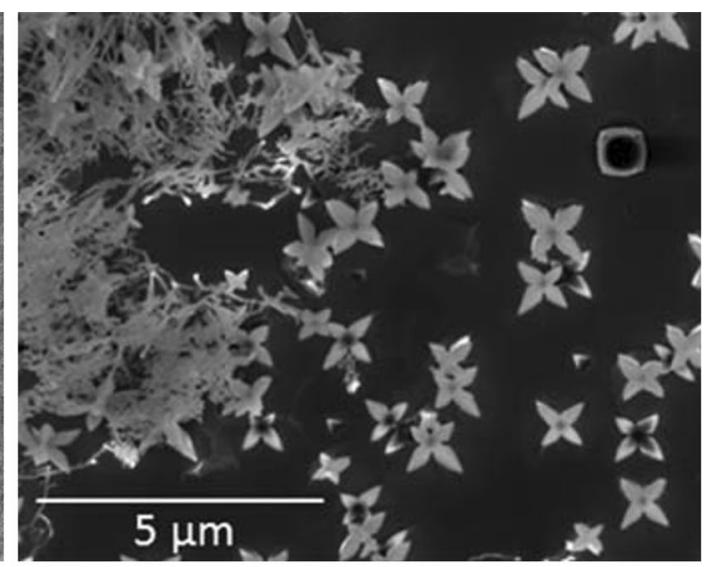

(b)

Fig. 4 (a) HRTEM micrograph showing an amorphous Si-nitride particle (bottom right) in the ferrite matrix (near 100 zone axis) of an Fe1.6 at. $\% \mathrm{Si}$ alloy specimen nitrided at $550{ }^{\circ} \mathrm{C}$ for $112 \mathrm{~h}$ with a nitriding potential of $0.078 \mathrm{~atm}^{-1 / 2}$. From Ref 35 ; (b) SEM micrograph recorded from the cross-section of an $\mathrm{Fe}-4.5$ at. $\% \mathrm{Si}$ alloy specimen nitrided at $650{ }^{\circ} \mathrm{C}$ for $48 \mathrm{~h}$ with a nitriding potential of 0.02 atm ${ }^{-1 / 2}$ showing amorphous, octapod-shaped $\mathrm{Si}_{3} \mathrm{~N}_{4}$ precipitates (right) and finer, crystalline $\alpha-\mathrm{Si}_{3} \mathrm{~N}_{4}$ precipitates, from Ref 37 
matrix only with great difficulty, and surprisingly its precipitation occurs by initially forming an amorphous (this is highly unusual for precipitation of a solid second phase in a solid, supersaturated matrix) metastable (Ref 35) precipitate which can later, or at more elevated temperature, crystallize (Ref 36, 37, 53) (see Fig. 4).

\section{Ternary Alloys}

In steels, often more than one (dissolved) alloying element is present that can interact with nitrogen such that nitride precipitation can occur. To date, the nitriding behavior of a number of ternary model alloys has been investigated systematically: Fe-Cr-Al (Ref 54-57), Fe-Cr-Ti (Ref 58), Fe-Cr-V (Ref 59), Fe-Cr-Mo (Ref 46, 48), Fe-Cr-Si (Ref 60), Fe-V-Si (Ref 60, 61), Fe-Ti-Si (Ref 60), Fe-V-Al (Ref 59), Fe-Ti-Al (Ref 59), and Fe-Ti-Mo (Ref 62), and of one quaternary Fe-Cr-Mo-V alloy (Ref 49). A focus of interest here is the question: how do the alloying elements $\mathrm{Me}_{1}$ and $\mathrm{Me}_{2}$, if present together, interact with $\mathrm{N}$ : do mixed $\left(\mathrm{Me}_{1}, \mathrm{Me}_{2}\right) \mathrm{N}_{x}$ nitrides occur, and if not, how are the separate precipitation processes of $\mathrm{Me}_{1} \mathrm{~N}_{x}$ and $\mathrm{Me}_{2} \mathrm{~N}_{x}$ affected?

In many cases, the precipitation of mixed $\left(\mathrm{Me}_{1}, \mathrm{Me}_{2}\right) \mathrm{N}_{x}$ nitrides was found to occur: thus (Cr,Al)N (Ref 54-57), $(\mathrm{Cr}, \mathrm{Ti}) \mathrm{N}(\operatorname{Ref} 58),(\mathrm{Cr}, \mathrm{V}) \mathrm{N}(\operatorname{Ref} 59)$, and $(\mathrm{Cr}, \mathrm{Mo}) \mathrm{N}_{x}(\operatorname{Ref} 46$, 48) were detected.

However, the mixed nitrides are metastable with respect to decomposition into $\mathrm{Me}_{1} \mathrm{~N}$ and $\mathrm{Me}_{2} \mathrm{~N}$ : as a consequence of kinetic constraints the system accepts a less than maximal gain (i.e., release) of (total) Gibbs energy by allowing the more slowly precipitating element to be taken up in the initially precipitating nitride particles. The change of the precipitate/matrix volume misfit for the mixed nitride as compared to the binary nitride can but need not play a dominant role here: in the case of TiN, the uptake of $\mathrm{Cr}$, of smaller atomic size, leads to a favorable, i.e., decreased, volume misfit; in the case of $\mathrm{CrN}$, the uptake of Mo, of larger atomic size, leads to an unfavorable, i.e., increased, volume misfit; for the development of $(\mathrm{Cr}, \mathrm{Al}) \mathrm{N}$, see Ref 54-57. In all these cases, mixed nitrides are formed.

In those systems where in principle, a stable ternary nitride phase can develop that, from a crystallographic point of view, does not occur in the binary boundary systems, such as $\mathrm{CrMoN}_{2}$ (Ref 46), $\mathrm{MnSiN}_{2}$ (Ref 63), and CrTaN (Ref 64), also such nitrides may occur in practice.

If the precipitation kinetics of the two nitride forming elements are, separately, (very) largely different, as e.g., V and Al (Ref 59), Ti and Al (Ref 59), and Ti and Mo (Ref 62), the initially forming nitride precipitates so fast that then separate precipitation of binary nitrides is observed. The slower nitride forming element may not be incorporated (in significant amounts) in time or the $\mathrm{Me}_{1}-\mathrm{Me}_{2}$ interaction is unfavorable. Such behavior may especially occur if the crystal structures of the binary, boundary nitrides of the nitride forming elements are very different. This for example holds for Fe-Ti/V/Cr-Si alloys (Ref 60, 61). In this case, the sequential precipitation of the binary nitrides is observed. Then the presence of the nitride particles of the faster forming element may have an accelerating (TiN), or decelerating (VN) effect on the subsequent precipitation of the more slowly reacting alloying element, due to a faster or slower, respectively, coherent $\rightarrow$ incoherent transition for the $\mathrm{Me}_{1}(\mathrm{Ti}, \mathrm{V}, \mathrm{Cr}) \mathrm{N} / \boldsymbol{\alpha}-\mathrm{Fe}$ interface. The subsequent

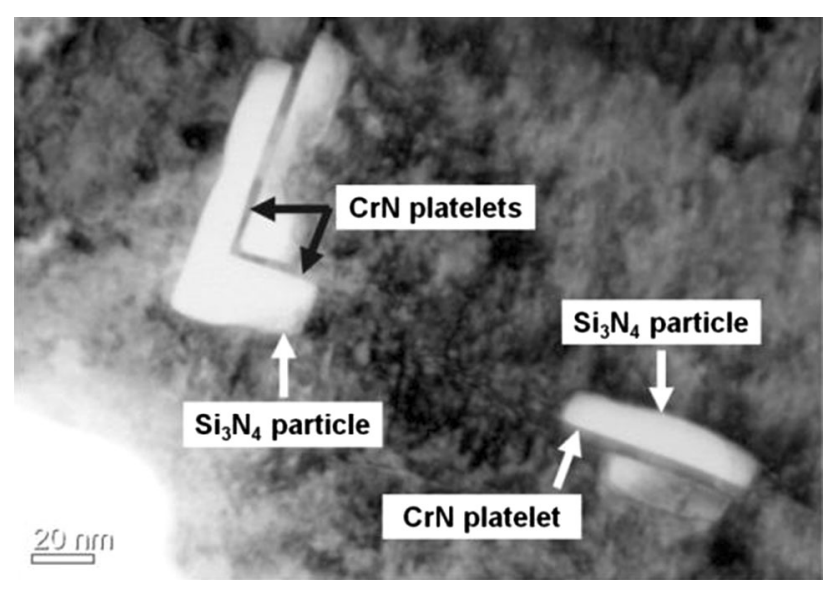

Fig. 5 TEM bright field of an Fe-2.0 at.\%Cr-2.0 at.\%Si alloy specimen nitrided at $580{ }^{\circ} \mathrm{C}$ for $648 \mathrm{~h}$ with a nitriding potential of $0.1 \mathrm{~atm}^{-1 / 2}$ Amorphous $\mathrm{Si}_{3} \mathrm{~N}_{4}$ particles grow along the faces of $\mathrm{CrN}$ platelets. From Ref 60

precipitation of amorphous $\mathrm{Si}_{3} \mathrm{~N}_{4}$ particles occurs preferentially at the incoherent $\mathrm{Me}_{1} \mathrm{~N} / \alpha-\mathrm{Fe}$ interface (Ref 60) (see Fig. 5).

Considering the various studies on nitrided ternary Fe-based alloys, three categories of ternary systems can now be distinguished on the basis of the similarity of the crystal structures of the binary boundary nitrides and the difference of the (separate) interaction parameters of the nitride forming elements (Ref 48):

(i) Systems where the crystal structures of the binary boundary nitrides are similar and the interaction parameter difference of the nitride forming elements is moderate. This is the case in the ternary Fe-Cr-Al, Fe-Cr-Ti, Fe-Cr-Mo, and $\mathrm{Fe}-\mathrm{Cr}-\mathrm{V}$ systems; mixed ternary nitrides develop in these systems.

(ii) Systems where the crystal structures of the binary boundary nitrides are similar but the interaction parameter difference of the nitride forming elements is large. This is the case in the ternary Fe-Ti-Al, Fe-Ti-Mo, and Fe-V-Al systems; separate binary nitrides develop in these systems.

(iii) Systems where the crystal structures of the binary boundary systems are dissimilar. This is the case in the Fe-Ti-Si, Fe-Cr-Si, and Fe-V-Si systems; separate binary nitrides develop in these systems.

\section{Excess Nitrogen and Nitride Composition}

\subsection{Types of Absorbed Nitrogen}

In ferritic, nitrided Fe-based alloys, the nitrogen content of the nitrided zone is often distinctly larger than what is expected for (i) the precipitation of all alloying element as nitride of the expected, equilibrium composition (e.g., $\mathrm{MeN}$ or $\left(\mathrm{Me}_{1}, \mathrm{Me}_{2}\right) \mathrm{N}$, see sections 3 and 6), and (ii) the equilibrium amount of nitrogen dissolved in the ferrite matrix (under the given nitriding conditions). The nitrogen additionally present is referred to as "excess nitrogen" (Ref 3, 10, 28, 44). 
In the CP microstructure, excess nitrogen can be present (see Fig. 6) either (i) adsorbed at the precipitate/matrix interfaces or (ii) dissolved in the strained ferrite matrix. Due to the very fine size and consequently large precipitate/matrix interfacial area of the nitride precipitates and the large misfit strains associated with the coherent nature of the nitride-platelet/matrix interface, the amount of excess $\mathrm{N}$ can be very large: in nitrided Fe-Ti alloys, the total nitrogen content can be three times as high as the Ti content of the alloy (Ref 10 ), although $\mathrm{Ti}$ is known to precipitate as TiN. In general, the stronger the Me-N interaction, the more excess nitrogen can be taken up by the alloy. Note that when the precipitation morphology changes, especially if drastic coarsening occurs as e.g., by DC, then the capacity for excess nitrogen uptake changes (strongly reduces) (Ref 65, 66). See Fig. 6 for a schematic representation of the various types of nitrogen absorbed in Fe-Me alloys.

The various types of nitrogen can be determined by recording so-called "nitrogen-absorption isotherms" (Ref 28, $31,44,65)$ as follows. Initially, a specimen is homogeneously (through) nitrided in order to precipitate all alloying element, $\mathrm{Me}$, as nitride in a morphology that is stable at the (lower) temperature where the absorption isotherm is recorded. Subse- quently, the specimen is annealed at lower temperature (usually in the range of $400-480{ }^{\circ} \mathrm{C}$ ), in a reducing atmosphere. This removes from the specimen all nitrogen dissolved in the matrix and, with the exception of $\mathrm{Me}=\mathrm{Al}(\operatorname{Ref} 31)$, also the nitrogen adsorbed at the nitride-platelet/matrix interfaces; the nitrogen strongly bound in the alloying element nitrides remains. This treatment may be performed in flowing $\mathrm{H}_{2}$ atmosphere or an atmosphere of minimal nitrogen activity to avoid, especially upon long-time treatment, the (partial) dissolution of even relatively stable alloying element nitrides (Ref 67).

The nitrogen strongly bound in the alloying element nitrides can be determined from the nitrogen content of the specimen in the denitrided state (i.e., from weight measurements before and after denitriding (level " $A$ " in Fig. 7). Subsequently, the specimen is nitrided with increasing nitriding potential (Ref 2); the nitrogen content (determined from the weight change) shows a linear dependency on the nitriding potential [as prescribed by thermodynamics (Ref 2, 44)]. The interface adsorbed excess nitrogen is determined from the intercept of this straight line with the ordinate (at a nitriding potential of 0 , difference of levels "B" and "A" in Fig. 7), and the dissolved excess nitrogen is given by the difference of the linear parts of
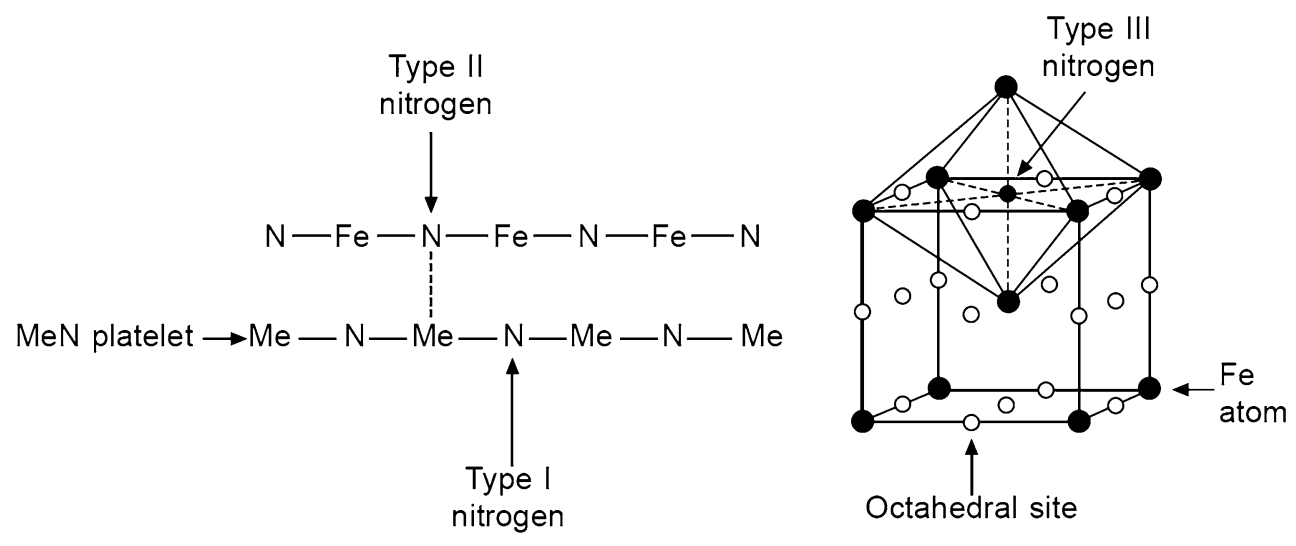

Fig. 6 Schematic representation of the types of absorbed nitrogen in nitrided Fe-Me alloys: strongly bound in the alloyng element nitrides (type I), adsorbed at the nitride/matrix interface (type II), and dissolved in the ferrite matrix (type III). From Ref 3

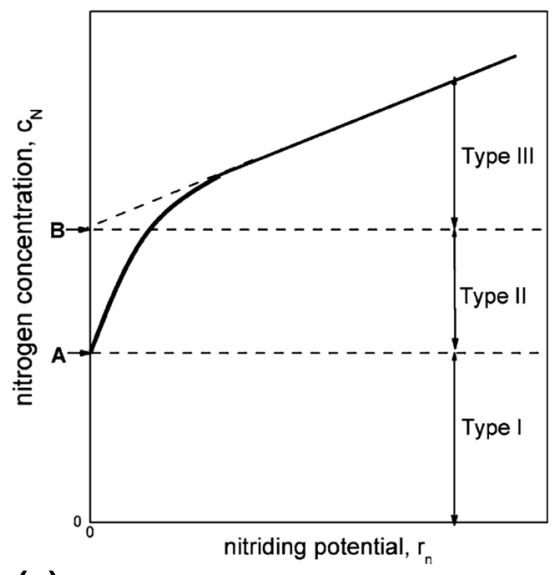

(a)

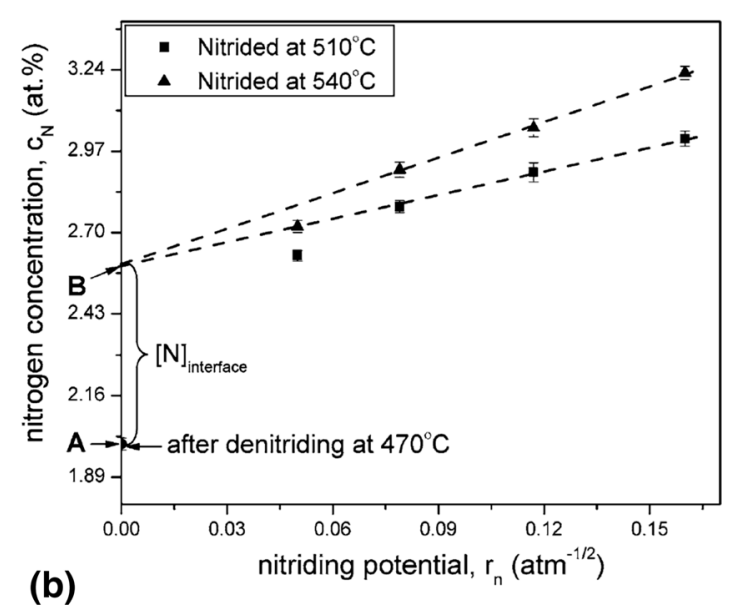

(b)

Fig. 7 (a) Schematic absorption isotherm of a nitrided Fe-Me alloy; (b) experimental absorption isotherm of Fe-2.23 at.\%V alloy, (pre-)nitrided at $550{ }^{\circ} \mathrm{C}$ for $26 \mathrm{~h}$ with a nitriding potential of $0.103 \mathrm{~atm}^{-1 / 2}$, subsequently denitrided at $470{ }^{\circ} \mathrm{C}$ for $42 \mathrm{~h}$ in pure, flowing $\mathrm{H}_{2}$. Absorption isotherms were then recorded at $510^{\circ} \mathrm{C}$ and $540{ }^{\circ} \mathrm{C}$. From Ref 65 
the absorption isotherms of the alloy specimen and that of pure $\mathrm{Fe}$ (Ref 68). Such analyses have been performed, e.g., in Ref 23, $28,31,65,66,69$. The various amounts of nitrogen in the specimen need to be known to develop a physically based model of the nitriding process (Ref 70, 71); the presence of excess nitrogen influences hugely the nitriding kinetics (Ref 70, 71).

\subsection{Nitride Composition; Fe in Me-Nitrides?}

Due to the very small size of the alloying element nitride precipitates, a direct, local determination of the composition of a nitride particle in the iron-based matrix is associated with a number of difficulties (Ref 46, 57, 72).

Local elemental analysis by an atom probe (AP) method (as atom probe tomography; APT) and (scanning) transmission electron microscopy ((S)TEM) coupled with either energydispersive $\mathrm{x}$-ray spectroscopy (EDX) or electron energy loss spectroscopy (EELS) has been performed on a number of nitrided Fe-based alloys (Ref 25, 46, 55, 57, 59, 72-74). These methods would in principle be able, for example, to show whether or not co-enrichment of nitride forming alloying elements occurs, e.g., to demonstrate the occurrence of ternary alloying element nitrides in nitrided $\mathrm{Fe}-\mathrm{Me}_{1}-\mathrm{Me}_{2}$-alloys.

Two major limitations are associated with the application of the above described methods to iron-based specimens (tips for APT; foils for (S)TEM): (i) the methods are of very limited accuracy for quantification of the nitrogen content of a singlenitride particle (Ref 46, 57, 72); and (ii) a considerable amount of matrix atoms/element (in this case Fe) is erroneously detected as inside the precipitates (see discussions in Ref 46, 57 for APT and in Ref 75 for electron microscopy).

This has led to a discussion in the literature, raging till today, whether $\mathrm{Fe}$ is present or not to a significant amount in the nitride precipitates [e.g., see ( $\operatorname{Ref} 65,72,73,76)$ ]. Previous AP analysis suggested that especially the nitrides in nitrided Fe-Mo alloys would contain large amounts of Fe (Ref 45, 77). However, such presence of Fe was made highly doubtful already by Mössbauer spectroscopy (Ref 9) of nitrided Fe-Mo and Fe-Ti alloys, and especially the comparative (APT, TEM, extraction replicas, and absorption isotherms) work and considerations in Ref 46, 57 appear to rule out that Fe is taken up to a significant amount in the alloying element nitrides. Denitrid- ing experiments, as performed in the course of a nitrogenabsorption isotherm analysis described in section 7.1, provide the most accurate (although indirect) route at present to determine the nitride composition ( $\operatorname{Ref} 23,28,31,46,65-67,69)$.

\section{Macro- and Microstresses/Strains in the Nitrided Microstructure}

The fine size and (semi-)coherent nature of the alloying element nitride precipitates in the ferrite matrix is chiefly responsible for the improvement of the mechanical (e.g., fatigue) properties of the nitrided component. The large volumetric misfit of nitride precipitates and ferrite matrix (see Table 1) leads to a considerable tendency for the nitrided zone to expand. However, as the nitride zone is constrained by its adherence to the (rigid) unnitrided core, high compressive (residual) macrostress is present parallel to the surface in the surface adjacent region (Ref $24,48,78,79)$. Upon relaxation of the nitrided zone, e.g., by DC (Ref 24), the compressive macrostress at the surface relaxes, and may even turn to a tensile macrostress, if the relaxed region is "on top" of a "freshly nitrided" region [see Fig. 8; (Ref 24, 79, 80)].

Apart from the macrostress induced by the macroscopic misfit of nitrided case and unnitrided core, discussed in the preceding paragraph, the strongly varying state of stress around the individual nitride platelets leads to a variation of microstrain on an atomic scale (see further below).

Residual macrostresses can be determined conveniently by (x-ray) diffraction methods utilizing the position of the maximum of the diffraction profiles/diffraction peaks (Ref 79, 81,82 ). The complex evolution of the shape and position of the (ferrite matrix) diffraction peaks upon nitriding was observed and discussed in Ref 83 and 84, respectively. To facilitate the interpretation in these experiments, and pertaining to the discussion below, the specimens were through, i.e., homogeneously nitrided, so that a contribution to macrostress due to a nitrided case/unnitrided core misfit (as discussed in the beginning of this section) does not occur.

Initially (Fig. 9b), the precipitate/matrix misfit is accommodated fully elastically leading to the homogeneous expansion of
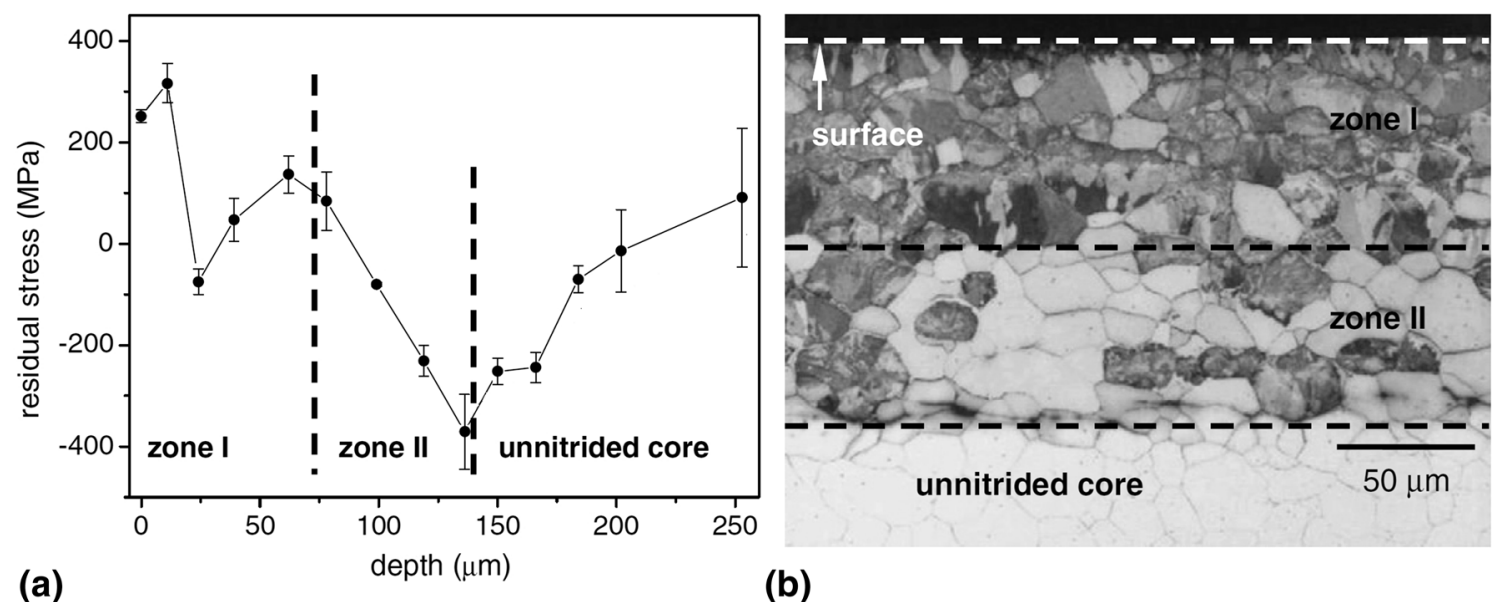

(b)

Fig. 8 (a) residual stress depth profile and (b) corresponding optical micrograph of the nitrided zone of an Fe- 8 wt.\%Cr alloy, nitrided at $580{ }^{\circ} \mathrm{C}$ for $6 \mathrm{~h}$ with a nitriding potential of $0.1 \mathrm{~atm}^{-1 / 2}$. From Ref 24 


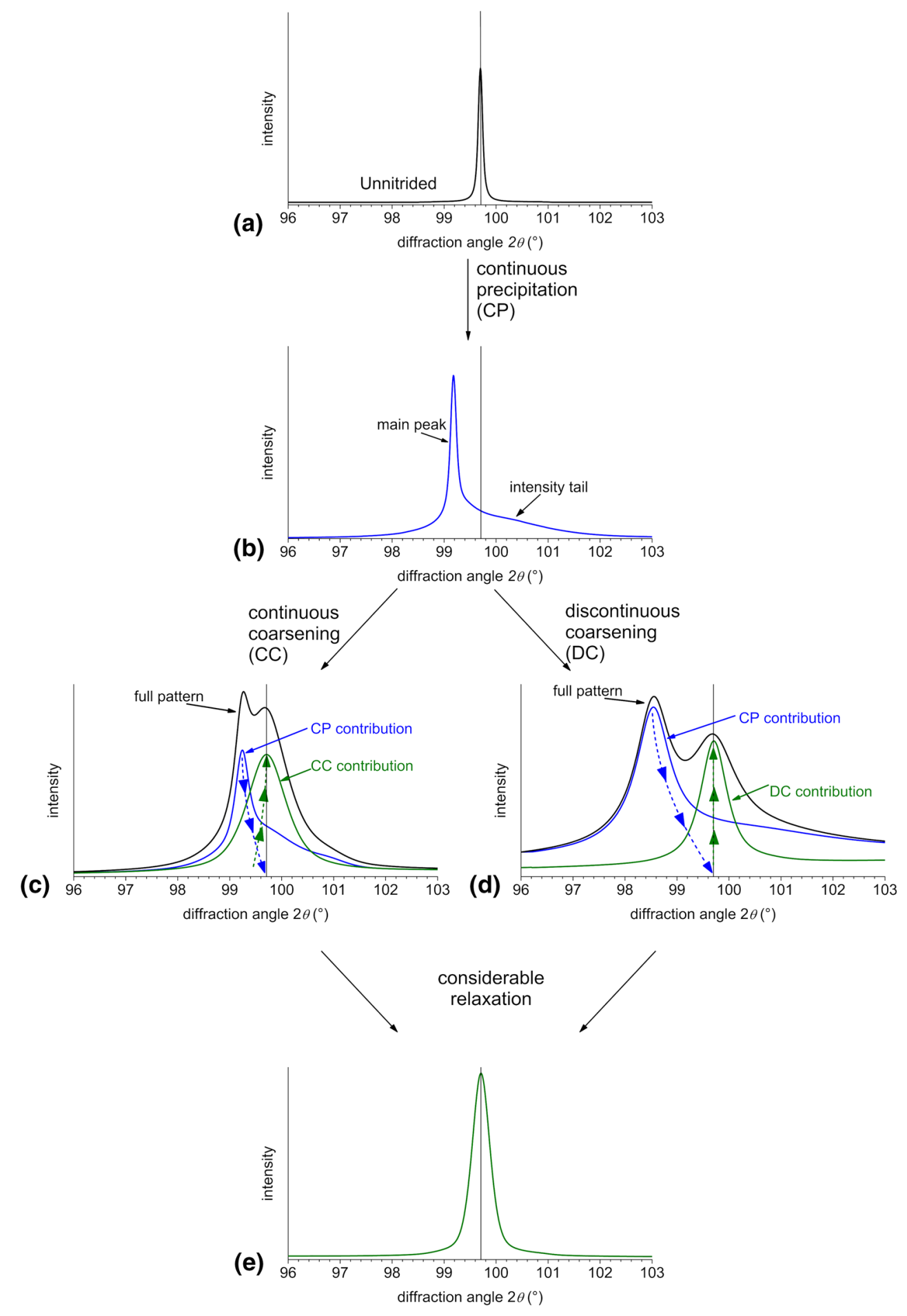

Fig. 9 Schematic evolution of the diffraction peaks of nitrided Fe-based alloys. From Ref 83

the ferrite matrix due to the hydrostatic tensile component of the nitride/matrix misfit stress field. Correspondingly, the diffraction peaks shift toward lower diffraction angles. This peak shift can be predicted quantitatively employing a misfitting inclusion model and considering that matrix and precipitates diffract coherently, i.e., as one assembly (see also Ref 85). The presence of severely distorted regions in the immediate vicinity of the nitride platelets leads to the emergence of an intensity tail of the diffraction peaks toward higher diffraction angles (Ref 84).
Upon continued nitriding (=aging of the nitrided microstructure) coarsening occurs and the nitride-precipitate particles lose their coherency with the ferrite matrix: the precipitate/matrix assembly no longer diffracts coherently. Then separate matrix and precipitate reflections can be observed, provided a sufficiently high volume fraction of precipitates is present in the diffracting volume $(\operatorname{Ref} 83,85)$. The coarsening process can occur in a continuous manner (CC) and, possibly, in alloys with a larger alloying element/precipitate content, also in a discontinuous manner (cf. section 4) (Ref 83). Both processes can be 
tracked from changes in the diffraction-peak position and the diffraction-peak shape: in the case of continuous coarsening, which occurs by the slow growth of the nitride platelets under gradual loss of the coherency with the matrix, the relaxation proceeds locally leading to a heterogeneous degree of stress relaxation throughout the whole nitrided microstructure. This is accompanied by a gradual decrease of the ferrite matrix expansion and the emergence of a separate, still considerably broadened ferrite diffraction peak corresponding to the relaxed regions (Fig. 9c); thus split ferrite diffraction peaks occur. In the case of discontinuous coarsening, the immediate and full relaxation at the (moving) $\mathrm{CP} / \mathrm{DC}$ interface leads (already from the onset of discontinuous coarsening) to the emergence of a separate, sharp (DC-)ferrite peak at the position of the fully relaxed ferrite matrix, while the (CP-)ferrite peak only marginally relaxes by the much slower continuous coarsening process (Fig. 9d); thus also in this case, split ferrite diffraction peaks occur. The processes can be well distinguished due to the different evolutions of the diffraction peaks (as a function of time) during coarsening.

\subsection{Macrostress as Origin of Anisotropic Nitriding Rate}

Very recently dedicated experiments have shown that the nitrided zone depth depends on the crystallographic orientation of individual ferrite matrix grains in the surface adjacent region with respect to the specimen surface (Ref 86). It was found that the compressive macrostress parallel to the surface in the surface adjacent region (developing as a consequence of the nitrided case/unnitrided core misfit [see begin of section 8]) depends on the crystallographic orientation of the grain as consequence of the intrinsic elastic anisotropy of the matrix grains. The variation of compressive macrostress parallel to the surface from grain to grain implies that the hydrostatic component of stress equivalent to this compressive stress varies from grain to grain. As a consequence, the nitrogen solubility varies from grain to grain (i.e., depends on the crystallographic orientation of the grain with respect to the surface) and, consequently, so does the nitrided depth (see Fig. 10a and b). Indeed, grains with an elastically stiff direction perpendicular to the surface (as grains with a $\{111\}$ plane parallel to the surface) show a smaller nitrogen solubility and smaller nitrided depth than grains with an elastically soft direction perpendicular to the surface (as grains with a $\{100\}$ plane parallel to the surface). Note that once the nitrided depth becomes (much) larger than the grain size, these differences disappear as the stress level decreases because the specimen gradually approaches a state of homogeneous (through) nitriding. Finally, it is noted that for pure ferrite (no alloying elements), the compressive nature of the macrostress parallel to the surface and also of the equivalent hydrostatic stress in general leads to a nitrogen solubility smaller than in the absence of stress, but this solubility likely will be different for each grain at the surface as long as the specimen has not been nitrided homogeneously.

\section{The Role of Carbon}

Despite the obvious practical significance and the vast number of studies on the nitriding behavior of technical steels, only very few fundamental studies have been devoted to understanding the role of carbon in the diffusion zone (Ref 87 , 88). The major consequences for the microstructure of the nitrogen diffusion zone of the presence of carbon are known, but the operating mechanisms are only crudely understood.

In general, as follows from their Gibbs energies of formation, carbides are less stable than nitrides. For example, at $773 \mathrm{~K}$ $\left(500^{\circ} \mathrm{C}\right)$, the Gibbs energy of formation of $\Delta G^{f}=$ $-268 \mathrm{~kJ} \mathrm{~mol}^{-1}$ per mole Ti for TiN and it is $-174 \mathrm{~kJ} \mathrm{~mol}^{-1}$ per mole Ti for TiC (Ref 89). It indicates that carbides, which may be present as a result of a previous tempering treatment, are replaced, i.e., dissolved and reprecipitated or transformed directly, to nitrides during the nitriding treatment. This is observed indeed ( $\operatorname{Ref} 87,88,90)$, see also (Ref 73).

The thereby released carbon now is free to diffuse in the specimen. If a compound layer can form on the specimen surface (cf. section 1), i.e., at sufficiently high chemical potentials of nitrogen (and carbon) in the surrounding atmosphere, it may become incorporated into the compound layer. If no compound layer can form on the specimen surface, carbon may escape into the atmosphere. In a constantly renewed purely
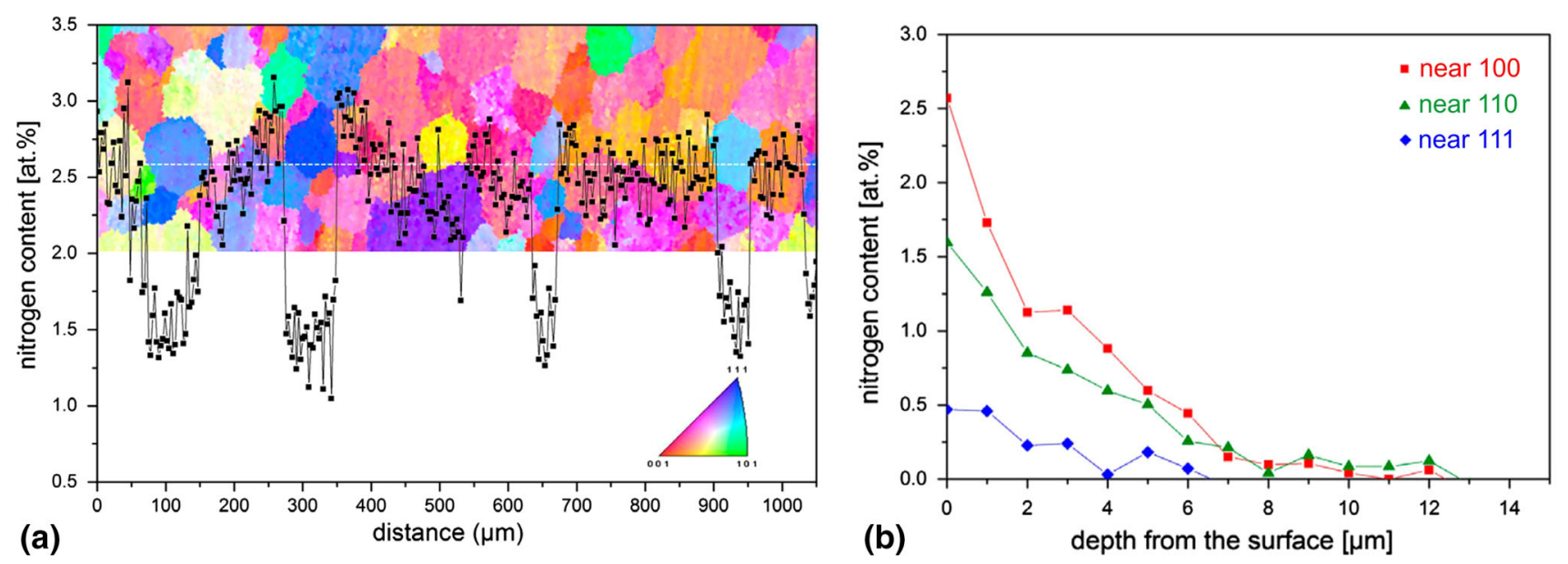

Fig. 10 Dependence of (a) the surface nitrogen content and (b) the nitrided depth on the grain orientation of a nitrided Fe-4.5 at.\%Cr alloy specimen nitrided at $450{ }^{\circ} \mathrm{C}$ for $3 \mathrm{~h}$ with a nitriding potential of $0.1 \mathrm{~atm}^{-1 / 2}$. The solubility and the nitriding depth of grains with an orientation (close to one) with $\{111\}$ lattice planes parallel to the surface are relatively small. From Ref 86 


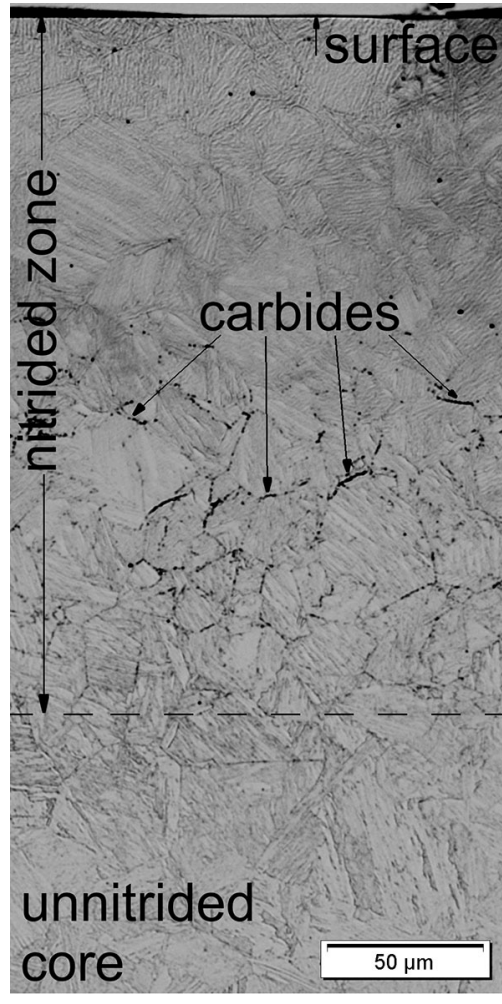

Fig. 11 Light optical micrograph of the surface adjacent region of a previously martensitically hardened $\mathrm{Fe}-1.75$ at.\%Cr- 0.25 at.\%Mo0.61 at. $\% \mathrm{C}$ alloy specimen nitrided at $580{ }^{\circ} \mathrm{C}$ for $3 \mathrm{~h}$ with a nitriding potential of $0.1 \mathrm{~atm}^{-1 / 2}$. Close to the nitrided surface a decarburized region is found, below which a region with cementite development along prior austenite-grain boundaries parallel to the specimen surface occurs. From Ref 96

nitriding atmosphere (involving a chemical potential of carbon equal to nil), thermodynamics dictate that all carbon should leave the specimen.

Especially at larger depths in the specimen, the carbon released by the nitride formation may lead to local supersaturation of carbon such that carbon precipitates as cementite, $\mathrm{Fe}_{3} \mathrm{C}$, at easy nucleation sites, such as prior austenite-grain boundaries. The compressive macrostress developing upon nitriding in the diffusion zone parallel to the surface (cf. begin of section 8) imposes a preferred development of the cementite on grain boundaries more or less parallel to the surface, as this allows to (partially) accommodate this macrostress state (see Fig. 11).

\section{Conclusion}

Control of the properties of nitrided, iron-based components requires understanding of, at least, the parameters governing the alloying element $(\mathrm{Me})$ nitride $\left(\mathrm{MeN}_{x}\right)$ particle constitution, crystal structure, and morphology, the nitrogen content depth profile and the nitriding kinetics.

The strength of the interaction of $\mathrm{Me}$ and $\mathrm{N}$, at the background of the observed phenomena, can be crudely characterized by [(the negative of) the ratio of] the chemical Gibbs energy driving the precipitation of $\mathrm{MeN}_{x}$ and the counteracting misfit-strain energy. The (strived for) crystal structure of the nitride may be largely incompatible with that of the ferrite matrix, leading to precipitation of metastable nitrides of non-equilibrium crystal structure or even of amorphous nature.

The development of residual macro- and microstresses/ strains reflects the macroscopic nitrided case/unnitrided core misfit, and the microscopic variation of strain around the misfitting, nano-sized nitride precipitates. The microstructural development (precipitation followed by coarsening) expresses itself by changes in the state of stress, which can be traced by dedicated diffraction analysis.

The variation of the state of macrostress from grain to grain at the surface induces (local) differences of the nitrogen solubility and thus differences of the nitrided depth for grains with different crystallographic orientation with respect to the surface.

The kinetics of nitride precipitation can be drastically influenced by the developing misfit-strain fields and the rate of their relaxation by the coherent $\rightarrow$ incoherent transition of the Me-nitride/ $\alpha$-Fe interfaces.

It is nowadays possible to precisely determine the various types of (excess) nitrogen present in the nitrided microstructure. With this knowledge, physically based models are being developed that can describe the nitriding behavior (see Ref 71).

In the past, fundamental research focused on the nitriding behavior of binary iron-based alloys. Only in recent years, attention has been devoted to the nitriding of ternary (in one case even quaternary) iron-based alloys. Evidently, the nitriding response of the latter alloys is not a simple extrapolation of that of the binary alloys. Thus, the road to full control of the nitriding process has not at all been trod till the end and it can be expected that scientific discoveries and challenges ahead of us will lead to new, fascinating technological possibilities of the nitriding process.

\section{Acknowledgment}

Open access funding provided by Max Planck Society (Institute for Intelligent Systems). The authors are especially grateful to their colleagues and coworkers during the last years: Dr. Sai Ramudu Meka (now at Indian Institute of Technology, Roorkee, India), Dr. Maryam Akhlaghi and Dr. Ewald Bischoff (Max Planck Institute for Intelligent Systems, Stuttgart, Germany).

\section{Open Access}

This article is distributed under the terms of the Creative Commons Attribution 4.0 International License (http://creativecommons.org/ licenses/by/4.0/), which permits unrestricted use, distribution, and reproduction in any medium, provided you give appropriate credit to the original author(s) and the source, provide a link to the Creative Commons license, and indicate if changes were made.

\section{References}

1. C.M. Cotell, J.A. Sprague, and F.A. Smidt, Ed., ASM Handbook Volume 5: Surface Engineering, ASM International, Materials Park, 1994

2. E.J. Mittemeijer, Fundamentals of Nitriding and Nitrocarburizing, $A S M$ Handbook, Volume 4A, Steel Heat Treating Fundamentals and Processes, J. Dosset and G.E. Totten, Ed., ASM International, Materials Park, 2013, p 619-646 
3. E.J. Mittemeijer and M.A.J. Somers, Ed., Thermochemical Surface Engineering of Steels, 1st ed., Woodhead Elsevier, Cambridge, 2015

4. E.J. Mittemeijer, A.B.P. Vogels, and P.J. van der Schaaf, Morphology and Lattice Distortions of Nitrided Iron and Iron-Chromium Alloys and Steels, J. Mater. Sci., 1980, 15(12), p 3129-3140

5. E.J. Mittemeijer, A.B.P. Vogels, and P.J. van der Schaaf, Aging at Room Temperature of Nitrided $\alpha$-Iron, Scr. Metall., 1980, 14, p 411416

6. W.T.M. Straver, H.C.F. Rozendaal, and E.J. Mittemeijer, Consequences of the Heterogeneous Nitriding of $\alpha$-lron: Dislocation Production and Oriented Precipitation, Metall. Trans. A, 1984, 15(4), p 627-637

7. H. Göhring, S. Kante, A. Leineweber, and E.J. Mittemeijer, Microstructural Development and Crystallographic Properties of Decomposing Fe-N-C Compound Layers, Int. J. Mater. Res., 2015, 107. doi: $10.3139 / 146.111330$

8. M.A.J. Somers and E.J. Mittemeijer, Development and Relaxation of Stress in Surface Layers; Composition and Residual Stress Profiles in $\gamma^{\prime}$ $\mathrm{Fe}_{4} \mathrm{~N}_{1-\mathrm{x}}$ Layers on $\alpha$-Fe Substrates, Metall. Trans. A, 1990, 21, p 189-204

9. G.P. Huffman and H.H. Podgurski, Mössbauer Study of Nitrided FeMo and Fe-Ti Alloys, Acta Metall., 1975, 23(11), p 1367-1379

10. D.S. Rickerby, S. Henderson, A. Hendry, and K.H. Jack, Overview No. 51 Structure and Thermochemistry of Nitrided Iron-Titanium Alloys, Acta Metall., 1986, 34(9), p 1687-1699

11. D.S. Rickerby, A. Hendry, and K.H. Jack, Low-Temperature Aging of Nitrided Fe-Ti Alloys, Acta Metall., 1986, 34(10), p 1925-1932

12. M. Pope, P. Grieveson, and K.H. Jack, Nitride Precipitation in Ferritic Iron-Vanadium Alloys, Scand. J. Metall., 1973, 2, p 29-34

13. S. Bor and Ö.E. Atasoy, The Nitriding of Fe-V Alloys, Metall. Trans. $A, 1977,8(6)$, p $975-979$

14. J.-D. Kamminga and G.C.A.M. Janssen, Calculation of Nitrogen Depth Profiles in Nitrided Fe-Mn and Fe-V, Surf. Coatings Technol., 2005, 200(1-4), p 909-912

15. S.S. Hosmani, R.E. Schacherl, and E.J. Mittemeijer, Nitriding Behavior of $\mathrm{Fe}-4 \mathrm{wt} \% \mathrm{~V}$ and $\mathrm{Fe}-2 \mathrm{wt} \% \mathrm{~V}$ Alloys, Acta Mater, 2005, 53(7), p 2069-2079

16. N.E.V. Díaz, S.S. Hosmani, R.E. Schacherl, and E.J. Mittemeijer, Nitride Precipitation and Coarsening in Fe-2.23 at.\% V Alloys: XRD and (HR)TEM Study of Coherent and Incoherent Diffraction Effects Caused by Misfitting Nitride Precipitates in a Ferrite Matrix, Acta Mater., 2008, 56(16), p 4137-4149

17. B. Mortimer, P. Grieveson, and K.H. Jack, Precipitation of Nitrides in Ferritic Iron Alloys Containing Chromium, Scand. J. Metall., 1972, 1, p 203-209

18. P.M. Hekker, H.C.F. Rozendaal, and E.J. Mittemeijer, Excess Nitrogen and Discontinuous Precipitation in Nitrided Iron-Chromium Alloys, $J$. Mater. Sci., 1985, 20(2), p 718-729

19. R.E. Schacherl, P.C.J. Graat, and E.J. Mittemeijer, Gaseous Nitriding of Iron-Chromium Alloys, Z. für Metallkd., 2002, 93(5), p 468-477

20. M. Sennour, P.H. Jouneau, and C. Esnouf, TEM and EBSD Investigation of Continuous and Discontinuous Precipitation of $\mathrm{CrN}$ in Nitrided Pure Fe-Cr Alloys, J. Mater. Sci., 2004, 9, p 4521-4531

21. M. Sennour, C. Jacq, and C. Esnouf, Mechanical and Microstructural Investigations of Nitrided Fe-Cr Layers, J. Mater. Sci., 2004, 39(14), p 4533-4541

22. G. Miyamoto, A. Yonemoto, Y. Tanaka, T. Furuhara, and T. Maki, Microstructure in a Plasma-Nitrided Fe-18 mass\% $\mathrm{Cr}$ Alloy, Acta Mater., 2006, 54(18), p 4771-4779

23. S.S. Hosmani, R.E. Schacherl, and E.J. Mittemeijer, Nitrogen Absorption by Fe-1.04at.\%Cr Alloy: Uptake of Excess Nitrogen, $J$. Mater. Sci., 2008, 43(8), p 2618-2624

24. N.E.V. Díaz, R.E. Schacherl, L.F. Zagonel, and E.J. Mittemeijer, Influence of the Microstructure on the Residual Stresses of Nitrided Iron-Chromium Alloys, Acta Mater., 2008, 56(6), p 1196-1208

25. R. Wagner and S.S. Brenner, Morphology and Chemistry of Internally Nitrided Fe-3at.\% Mo, Acta Metall., 1978, 26(2), p 197-206

26. M.M. Yang and A.D. Krawitz, Resistometric Study of Fe-V and Fe-Mo Nitrided by Constant Activity Aging, Metall. Trans. A, 1984, 15(8), p 1545-1554

27. H. Selg, E. Bischoff, S.R. Meka, R.E. Schacherl, T. Waldenmaier, and E.J. Mittemeijer, Molybdenum-Nitride Precipitation in Recrystallized and Cold-Rolled Fe-1 at. pet Mo Alloy, Metall. Mater. Trans. A, 2013, 44(9), p 4059-4070

28. H.H. Podgurski, R. Oriani, F. Davis, J. Li, and Y. Chou, Nitrogenation of Fe-Al Alloys. Pt. 2. The Adsorption and Solution of Nitrogen in
Nitrogenated Fe-Al Alloys, Trans. Metall. Soc. AIME, 1969, 245, p 1603-1608

29. M.H. Biglari, C.M. Brakman, M.A.J. Somers, W.G. Sloof, and E.J. Mittemeijer, On the Internal Nitriding of Deformed and Recrystallized Foils of Fe-2 at\% Al, Z. für Metallkd., 84(2), p 124-131

30. M.H. Biglari, C.M. Brakman, and E.J. Mittemeijer, Crystal Structure and Morphology of AIN Precipitating on Nitriding of an Fe-2at.\% Al Alloy, Philos. Mag. A, 1995, 72(5), p 1281-1299

31. M.H. Biglari, C.M. Brakman, E.J. Mittemeijer, and S. van der Zwaag, Analysis of the Nitrogen Absorption Isotherms of Cold-Rolled Fe-2 at.\% Al Specimens with Different AIN Precipitate Dimensions, Philos. Mag. A, 1995, 72(4), p 931-947

32. M. Sennour and C. Esnouf, Contribution of Advanced Microscopy Techniques to Nano-precipitates Characterization: Case of AlN Precipitation in Low-Carbon Steel, Acta Mater., 2003, 51(4), p 943-957

33. S.R. Meka, E. Bischoff, S.S. Hosmani, and E.J. Mittemeijer, Interrelationships of Defects, Nitride Modification and Excess Nitrogen in Nitrided Fe-4.75 at.\% Al Alloy, Int. J. Mater. Res., 2014, 105(11), p 1057-1066

34. G.R. Booker and J. Norbury, A New Nitride Precipitate in Iron-Silicon Alloys, Nature, 1959, 184(4695), p 1311-1312

35. E. Mittemeijer, M. Biglari, A. Böttger, N.M. van der Pers, W. Sloof, and F. Tichelaar, Amorphous Precipitates in a Crystalline Matrix; Precipitation of Amorphous Si3N4 in $\alpha-F e$, Scr. Mater., 1999, 41(6), p 625-630

36. S.R. Meka, K.S. Jung, E. Bischoff, and E.J. Mittemeijer, Unusual Precipitation of Amorphous Silicon Nitride Upon Nitriding Fe-2at.\%Si Alloy, Philos. Mag., 2012, 92(11), p 1435-1455

37. S.R. Meka, E. Bischoff, B. Rheingans, and E.J. Mittemeijer, OctapodShaped, Nanosized, Amorphous Precipitates in a Crystalline Ferrite Matrix, Philos. Mag. Lett., 2013, 93(4), p 238-245

38. J. Baird, Precipitation of Nitrides in Iron-Manganese-Nitrogen Alloys, J. Iron Steel Inst., 1966, 204(11), p 1122-1130

39. J.F. Enrietto, The Solubility and Precipitation of Nitrides in Alpha-Iron Containing Manganese, Trans. Metall. Soc. AIME, 1961, 224, p 43-48

40. M. Gouné, A. Redjaïmia, T. Belmonte, and H. Michel, Identification and Characterization of a Novel Mn-N Nitride Formed in Fe-Mn-N Alloy, J. Appl. Crystallogr., 2003, 36(1), p 103-108

41. M. Gouné, T. Belmonte, A. Redjaïmia, P. Weisbecker, J. Fiorani, and H. Michel, Thermodynamic and Structural Studies on Nitrided Fe$1.62 \% \mathrm{Mn}$ and Fe-0.56\%V Alloys, Mater. Sci. Eng. A, 2003, 351(1-2), p 23-30

42. S.R. Meka, A. Chauhan, T. Steiner, E. Bischoff, P.K. Ghosh, and E.J. Mittemeijer, Generating Duplex Microstructures by Nitriding; Nitriding of Iron Based Fe-Mn Alloy, Mater. Sci. Technol., 2015, doi: 10.1179/1743284715Y.0000000098

43. E.J. Mittemeijer, Fundamentals of Materials Science, Springer, Berlin, 2011

44. M.A.J. Somers, R.M. Lankreijer, and E.J. Mittemeijer, Excess Nitrogen in the Ferrite Matrix of Nitrided Binary Iron-Based Alloys, Philos. Mag. A, 1989, 59(2), p 353-378

45. D.H. Jack and K.H. Jack, Invited Review: Carbides and Nitrides in Steel, Mater. Sci. Eng., 1973, 11(1), p 1-27

46. T. Steiner, S.R. Meka, B. Rheingans, E. Bischoff, T. Waldenmaier, G. Yeli, T.L. Martin, P.A.J. Bagot, M.P. Moody, and E.J. Mittemeijer, Continuous and Discontinuous Precipitation in $\mathrm{Fe}-1$ at. $\% \mathrm{Cr}-1$ at. $\% \mathrm{Mo}$ Alloy Upon Nitriding; Crystal Structure and Composition of Ternary Nitrides, 2015, submitted for publication

47. R.G. Baker and J. Nutting, The Tempering of a Cr-Mo-V-W and a MoV Steel, Iron Steel Inst. Spec. Rep., 1959, 64(Precipitation processes in steels), p 1-22

48. T. Steiner, S.R. Meka, E. Bischoff, T. Waldenmaier, and E.J. Mittemeijer, Nitriding of Ternary Fe-Cr-Mo Alloys; Role of the $\mathrm{Cr}$ / Mo-Ratio, Surf. Coatings Technol., 2016, 291, p 21-33

49. C.W. Kang, S.R. Meka, R.E. Schacherl, and E.J. Mittemeijer, Microstructure and Kinetics of Nitride Precipitation in a Quaternary Iron-Based Model Fe-2.82 at. pct $\mathrm{Cr}-0.13$ at. pct Mo-0.18 at. pct V Alloy, Metall. Mater. Trans. A, 2014, 46(1), p 328-336

50. D.B. Williams and E.P. Butler, Grain Boundary Discontinuous Precipitation Reactions, Int. Mater. Rev., 1981, 26(1), p 153-183

51. I. Manna, S.K. Pabi, and W. Gust, Discontinuous Reactions in Solids, Int. Mater. Rev., 2001, 46(2), p 53-91

52. M.H. Biglari, C.M. Brakman, E.J. Mittemeijer, and S. van der Zwaag, The Kinetics of the Internal Nitriding of Fe-2 at. pct Al Alloy, Metall. Mater. Trans. A, 1995, 26, p 765-776 
53. H.P. Van Landeghem, M. Gouné, S. Bordère, F. Danoix, and A. Redjaïmia, Competitive Precipitation of Amorphous and Crystalline Silicon Nitride in Ferrite: Interaction Between Structure, Morphology, and Stress Relaxation, Acta Mater, 2015, 93(10), p 218-234

54. K.S. Jung, R.E. Schacherl, E. Bischoff, and E.J. Mittemeijer, Nitriding of Ferritic Fe-Cr-Al Alloys, Surf. Coat. Technol., 2010, 204(12-13), p 1942-1946

55. A.R. Clauss, E. Bischoff, R.E. Schacherl, and E.J. Mittemeijer, Phase Transformation of Mixed $\mathrm{Cr}_{1-\mathrm{x}} \mathrm{Al}_{\mathrm{x}} \mathrm{N}$ Nitride Precipitates in Ferrite, Philos. Mag., 2009, 89(6), p 565-582

56. A.R. Clauss, E. Bischoff, S.S. Hosmani, R.E. Schacherl, and E.J. Mittemeijer, Crystal Structure and Morphology of Mixed $\mathrm{Cr}_{1-\mathrm{x}} \mathrm{Al}_{\mathrm{x}} \mathrm{N}$ Nitride Precipitates: Gaseous Nitriding of a Fe-1.5 Wt Pct Cr-1.5 Wt Pct Al Alloy, Metall. Mater. Trans. A, 2009, 40(8), p 1923-1934

57. M. Akhlaghi, S.R. Meka, E.A. Jägle, S.J.B. Kurz, E. Bischoff, and E.J. Mittemeijer, Low Temperature Nitriding of Recrystallized and ColdRolled Ferritic Fe-Cr-Al Alloy, in preparation

58. K.S. Jung, S.R. Meka, R.E. Schacherl, E. Bischoff, and E.J. Mittemeijer, Nitride Formation and Excess Nitrogen Uptake After Nitriding Ferritic Fe-Ti-Cr Alloys, Metall. Mater. Trans. A, 2011, 43(3), p 934-944

59. G. Miyamoto, S. Suetsugu, K. Shinbo, and T. Furuhara, Surface Hardening and Nitride Precipitation in the Nitriding of Fe-M1-M2 Ternary Alloys Containing A1, V, or Cr, Metall. Mater. Trans. A, 2015, 46(11), p 5011-5020

60. B. Schwarz, P.J. Rossi, L. Straßberger, F. Jörg, S.R. Meka, E. Bischoff, R.E. Schacherl, and E.J. Mittemeijer, Coherency Strain and Precipitation Kinetics: Crystalline and Amorphous Nitride Formation in Ternary FeTi/Cr/V-Si Alloys, Philos. Mag., 2014, 94(27), p 3098-3119

61. B. Schwarz, S.R. Meka, R.E. Schacherl, E. Bischoff, and E.J. Mittemeijer, Nitriding of Iron-Based Ternary Fe-V-Si Alloy: The Precipitation Process of Separate Nitrides, Acta Mater, 2014, 76, p 394-403

62. S. Henderson, Solute Interactions in Nitrided Iron Alloys, Ph. D. Thesis, University of Newcastle upon Tyne, 1976

63. W. Roberts, P. Grieveson, and K.H. Jack, Precipitation of Silicon Nitrides and Manganese-Silicon Nitrides in Steel, J. Iron Steel Inst., 1972, 210, p 931-937

64. H.K. Danielsen, J. Hald, and M.A.J. Somers, Atomic Resolution Imaging of Precipitate Transformation from Cubic TaN to Tetragonal CrTaN, Scr. Mater., 2012, 66(5), p 261-264

65. S.S. Hosmani, R.E. Schacherl, and E.J. Mittemeijer, Nitrogen Uptake by an Fe-V Alloy: Quantitative Analysis of Excess Nitrogen, Acta Mater., 2006, 54(10), p 2783-2792

66. S.S. Hosmani, R.E. Schacherl, L. Lityńska-Dobrzyńska, and E.J. Mittemeijer, The Nitrogen-Absorption Isotherm for $\mathrm{Fe}-21.5$ at. $\% \mathrm{Cr}$ Alloy: Dependence of Excess Nitrogen Uptake on Precipitation Morphology, Philos. Mag., 2008, 88(16), p 2411-2426

67. T. Steiner, S.R. Meka, H. Göhring, and E.J. Mittemeijer, Alloying Element Nitride Stability in Iron-Based Alloys; Denitriding of Nitrided Fe-V Alloys, Mater. Sci. Technol., 2016, doi:10.1080/02670836.2016.1155254

68. J. Stein, R.E. Schacherl, M. Jung, S.R. Meka, B. Rheingans, and E.J. Mittemeijer, Solubility of Nitrogen in Ferrite; The Fe-N Phase Diagram, Int. J. Mater. Res., 2013, 104(11), p 1053-1065

69. H.H. Podgurski and F.N. Davis, Thermochemistry and Nature of Nitrogen Absorption in Nitrogenated Fe-Ti Alloys, Acta Metall., 1981, 29(1), p 1-9

70. R.E. Schacherl, P. Graat, and E.J. Mittemeijer, The Nitriding Kinetics of Iron-Chromium Alloys; The Role of Excess Nitrogen: Experiments and Modelling, Metall. Mater. Trans. A, 2004, 35, p 3387-3398

71. M. Jung, S.R. Meka, B. Rheingans, and E.J. Mittemeijer, Coupling Inward Diffusion and Precipitation Kinetics; The Case of Nitriding Iron-Based Alloys, Metall. Mater. Trans. A, 2016, 47(3), p 1425-1439

72. B. Gault, F. Danoix, K. Hoummada, D. Mangelinck, and H. Leitner, Impact of Directional Walk on Atom Probe Microanalysis, Ultramicroscopy, 2012, 113, p 182-191

73. C. Ginter, L. Torchane, J. Dulcy, M. Gantois, A. Malchère, C. Esnouf, and T. Turpin, A New Approach to Hardening Mechanisms in the Diffusion Layer of Gas Nitrided $\alpha$-Alloyed Steels . Effects of Chromium and Aluminium: Experimental and Simulation Studies, La Metall. Ital., 2006, 7-8, p 29-35
74. P. Jessner, R. Danoix, B. Hannoyer, and F. Danoix, Investigations of the Nitrided Subsurface Layers of an Fe-Cr-Model Alloy, Ultramicroscopy, 2009, 109(5), p 530-534

75. D.C. Joy, A.D. Romig, and J.I. Goldstein, Principles of Analytical Electron Microscopy, Springer, Boston, MA, 1986

76. P. Jessner, M. Gouné, R. Danoix, B. Hannoyer, and F. Danoix, Atom Probe Tomography Evidence of Nitrogen Excess in the Matrix of Nitrided Fe-Cr, Philos. Mag. Lett., 2010, 90(11), p 793-800

77. J.H. Driver, D.C. Unthank, and K.H. Jack, Substitutional-Interstitial G.P. Zones in Nitrided Fe-Mo Alloys, Philos. Mag., 1972, 26(5), p 1227-1231

78. H. Selg, S.R. Meka, M. Kachel, R.E. Schacherl, T. Waldenmaier, and E.J. Mittemeijer, Nitriding Behaviour of Maraging Steel: Experiments and Modelling, J. Mater. Sci., 2013, 48(12), p 4321-4335

79. S.J.B. Kurz, S.R. Meka, N. Schell, W. Ecker, J. Keckes, and E.J. Mittemeijer, Residual Stress and Microstructure Depth Gradients in Nitrided Iron-Based Alloys Revealed by Dynamical Cross-Sectional Transmission X-Ray Microdiffraction, Acta Mater, 2015, 87, p 100-110

80. A.R. Clauss, E. Bischoff, R.E. Schacherl, and E.J. Mittemeijer, The Microstructure of the Diffusion Zone of a Gaseously Nitrided Fe-1 5 wt-\%Cr-1 5 wt-\%Al Alloy, Mater. Sci. Technol., 2010, 26(3), p 297308

81. U. Welzel, J. Ligot, P. Lamparter, A.C. Vermeulen, and E.J. Mittemeijer, Stress Analysis of Polycrystalline Thin Films and Surface Regions by X-Ray Diffraction, J. Appl. Crystallogr., 2005, 38(1), p 1-29

82. E.J. Mittemeijer and U. Welzel, Ed., Modern Diffraction Methods, Wiley VCH, Weinheim, 2013

83. T. Steiner, M. Akhlaghi, S.R. Meka, and E.J. Mittemeijer, DiffractionLine Shifts and Broadenings in Continuously and Discontinuously Coarsening Precipitate-Matrix Systems: Coarsening of Initially Coherent Nitride Precipitates in a Ferrite Matrix, J. Mater. Sci., 2015, 50(21), p 7075-7086

84. M. Akhlaghi, T. Steiner, S.R. Meka, A. Leineweber, and E.J. Mittemeijer, Lattice-Parameter Change Induced by Accommodation of Precipitate/Matrix Misfit; Misfitting Nitrides in Ferrite, Acta Mater., 2015, 98, p 254-262

85. M. Akhlaghi, T. Steiner, S.R. Meka, and E.J. Mittemeijer, MisfitInduced Changes of Lattice Parameters in Two-Phase Systems: Coherent/Incoherent Precipitates in a Matrix, J. Appl. Crystallogr., 2016, 49(1), p 69-77

86. M. Akhlaghi, M. Jung, S.R. Meka, M. Fonović, A. Leineweber, and E.J. Mittemeijer, Dependence of the Nitriding Rate of Ferritic and Austenitic Substrates on the Crystallographic Orientation of Surface Grains; Gaseous Nitriding of Fe-Cr and Ni-Ti Alloys, Philos. Mag., 2015, 95(36), p 4143-4160

87. P.C. Van Wiggen, H.C.F. Rozendaal, and E.J. Mittemeijer, The Nitriding Behaviour of Iron-Chromium-Carbon Alloys, J. Mater. Sci., 1985, 20(12), p 4561-4582

88. Y. Tomio, S. Kitsuya, K. Oh-ishi, K. Hono, G. Miyamoto, and T. Furuhara, Plasma Nitriding Behavior of Fe-C-M (M = Al, Cr, Mn, Si) Ternary Martensitic Steels, Metall. Mater. Trans. A, 2013, 45(1), p 239-249

89. M.W.J. Chase, NIST-JANAF Thermochemical Tables, 4th ed., American Chemical Society, Woodbury, 1998

90. P.F. Colijn, E.J. Mittemeijer, and H.C.F. Rozendaal, Light-Microscopical Analysis of Nitrided or Nitrocarburized Iron and Steels, Z. für Metallkd., 74(9), p 620-627

91. ICDD, JCPDS-International Centre for Diffraction Data, PCPDFWIN, 2002

92. W. Paszkowicz, S. Podsiadło, and R. Minikayev, Rietveld-Refinement Study of Aluminium and Gallium Nitrides, J. Alloys Compd., 2004, 382(1-2), p 100-106

93. S. Eriksson, Röntgenundersökningar över systemet järn-krom-kväve, Jernkontorets Ann., 1934, 118, p 530-543

94. P. Yang, H.-K. Fun, I.A. Rahman, and M.I. Saleh, Two Phase Refinements of the Structures of $\alpha-S i 3 N 4$ and $\beta-S i 3 N 4$ Made from Rice Husk by Rietveld Analysis, Ceram. Int., 1995, 21(2), p 137-142

95. A.Y. Ganin, L. Kienle, and G.V. Vajenine, Synthesis and Characterisation of Hexagonal Molybdenum Nitrides, J. Solid State Chem., 2006, 179(8), p 2339-2348

96. T. Pott, T. Steiner, and E. J. Mittemeijer, Nitriding of Fe-Cr-Mo-C Alloys, in preparation 